\title{
Introduction to "The Tensile Properties of Pearlite, Bainite, and Spheroidite," Transactions of the American Society for Metals, Vol. 30, Dec 1942, pp. 983-1020 by M. Gensamer, E. B. Pearsall, W. S. Pellini, and J. R. Low Jr.
}

Pioneering work was completed in the 1940s to establish the quantitative correlation of the microstructures observed in metals and alloys with the mechanical properties of these structures. In this paper, first published in 1942, the tensile properties of four steels were determined as a quantitative function of the measured dimensions of the aggregate structures pearlite and spheroidite, and of the austenite decomposition temperature for the structures pearlite and bainite.

This paper was selected as an ASM Classic paper by George E. Dieter, FASM, University of Maryland. According to Professor Dieter, "This paper presented the first quantitative correlation between yield strength in steels containing a two-phase microstructure of ferrite and cementite (annealed, normalized, and spheroidized steels). The authors found that the yield strength was inversely proportional to the logarithm of the mean interparticle spacing. Given that this was done before the days of automated quantitative metallography, it was quite a feat to assemble the data. The results of this paper were important in testing various theories of strengthening that were proposed in the next 20 years. It is worthy of note that three of the authors, Gensamer, Pellini, and Low, became very prominent metallurgists." 